\title{
Longevity after mechanical aortic root replacement—do men live longer?
}

\author{
Felix Girrbach, MD, Christian D. Etz, MD, PhD, Pascal M. Dohmen, MD, PhD, \\ Konstantin von Aspern, MD, Maximilian Luehr, MD, Michael A. Borger, MD, PhD, \\ Martin Misfeld, MD, PhD, Sandra Eifert, MD, PhD, and Friedrich-Wilhelm Mohr, MD, PhD
}

Objective: To investigate whether longevity after mechanical aortic root replacement is influenced by the patient's gender.

Methods: From February 1998 to June 2011, 476 patients ( 376 men, 100 women, mean age, $53 \pm 12$ years;
range, 18-88) underwent composite aortic root replacement. Of these patients, 398 ( 312 men) were included
in the present analysis. The indications for root replacement were aortic valve dysfunction (mostly stenosis)
and concomitant aneurysmal disease in $334(83.9 \%)$, acute type A aortic dissection in $51(12.8 \%)$, and infective
endocarditis in $10(2.5 \%)$. Other indications were technical or anatomic considerations $(0.8 \%)$.

Results: The women who presented for surgery were significantly older (men, $52 \pm 12$ years vs women, $56 \pm 12$ years; $P=.01)$. However, no significant differences were found with regard to previous cardiac surgery $(5.3 \%$, 20 men [6.4\%] vs 1 woman [1.2\%]; $P=.06)$, concomitant procedures $(38 \% ; 117$ men [37.5\%] vs 35 women $[40.7 \%] ; P=.62$ ), or additive EuroSCORE (men, $5.1 \pm 2.2$; women, $5.2 \pm 2.2 ; P=.55$ ). The mean diameter of the ascending aorta was not significantly different between the 2 groups (men, $54 \pm 9 \mathrm{~mm}$; women, $56 \pm 14 \mathrm{~mm}$; $P=.97$ ). The median follow-up period was 7.4 years (range, $0-13 ; 2366$ cumulative patient-years), with no significant difference in hospital mortality (men, $6.7 \%$ vs women, $10.5 \% ; P=.25$ ). Overall, men enjoyed significantly better longevity than did women. After 10 years, $73 \% \pm 3 \%$ of the men and only $60 \% \pm 6 \%$ of the women were alive $(P=.03)$. Although no long-term survival benefit for either gender was found in an age-matched subgroup among young patients $(P=.66)$, men experienced much more favorable longevity after 55 years of age $(P=.04)$. Consequently, the longevity in men—but not in women—was equal to an age-matched normal population.

Conclusions: Overall, long-term survival after mechanical aortic root replacement was significantly better among men. However, comparing age-matched subgroups $\leq 55$ years old, no significantly different life expectancy was found after mechanical root replacement. (J Thorac Cardiovasc Surg 2014;148:2087-95)

A variety of surgical options have become available for the treatment of aortic root disease. With the incentive to avoid long-term anticoagulation, valve-sparing aortic root procedures-such as the David or Yacoub procedure-have been progressively promoted during the previous 2 decades. ${ }^{1,2}$ However, these techniques require preservable valve leaflets and have therefore been mainly limited to mild or moderate aortic regurgitation. ${ }^{3}$ Aortic root replacement-offering versatility in terms of the valve dysfunction treated and reliability in terms of

\footnotetext{
From the Department of Cardiac Surgery, Heart Center Leipzig, University of Leipzig, Leipzig, Germany.

Disclosures: Authors have nothing to disclose with regard to commercial support. Drs F.G. and C.D.E. contributed equally to the present report.

Received for publication Oct 14, 2013; revisions received March 12, 2014; accepted for publication March 21, 2014; available ahead of print April 24, 2014.

Address for reprints: Felix Girrbach, MD, Department of Cardiac Surgery, Heart

Centre Leipzig, University of Leipzig, Struempellstrasse 39, Leipzig D-04289,

Germany (E-mail: felixfrederic.girrbach@herzzentrum-leipzig.de).

$0022-5223 / \$ 36.00$

Copyright $(2014$ by The American Association for Thoracic Surgery

http://dx.doi.org/10.1016/j.jtcvs.2014.03.042
}

longevity-remains the reference standard for various aortic pathologic entities affecting the aortic valve and root. $^{4}$

Since its invention in 1968 and after the initial experience, ${ }^{5,6}$ many modifications of the Bentall procedure have been developed until, in the early 1990s, the "biologic Bentall" was introduced-a "homemade" composite graft manufactured intraoperatively using stented bioprostheses. For the first time, it enabled root reconstruction in patients deemed unable to take anticoagulants. $^{7}$ The biologic Bentall offered excellent long-term survival, very low rates of thrombembolic and bleeding complications in the long term, with only 1 late reoperation for structural failure in a series of 275 consecutive patients. That series for the first time revealed a less favorable outcome after aortic root replacement in women. ${ }^{7}$ However, whether men also experience better longevity after mechanical aortic root replacement remains unclear.

Therefore, we investigated the potential gender-dependent outcome differences in a large cohort of mechanical aortic root replacements with the classic Bentall technique. 


\section{Abbreviations and Acronyms \\ $\mathrm{CPB}=$ cardiopulmonary bypass \\ PPM $=$ patient-prosthesis mismatch}

\section{METHODS}

In a review of our institutional database, including $>1200$ patients treated for aortic root disease, we found 476 consecutive patients (376 men $[79 \%]$ and 100 women [21\%]) who had undergone aortic root replacement with a mechanical conduit (ATS Medical, Minneapolis, Minn) from February 1998 to June 2011. A total of 78 patients were excluded because the valve morphology had not been clearly specified $(5 \%, \mathrm{n}=25)$, because of previous aortic valve replacement $(9 \%$, $\mathrm{n}=41)$, or because of Marfan syndrome $(2.5 \%, \mathrm{n}=12)$. Specification of the valve morphology was required because the gender distribution among patients with bicuspid aortic valves might be distinct from that of those with tricuspid aortic valves. A total of 398 patients with primary composite root replacement (312 men [78.4\%]; 86 women [21.6\%]) were included in the statistical analysis. Additional patient characteristics and preoperative data are listed in Table 1.

The indication for aortic root replacement was aortic valve pathologic features and an aneurysm of the aortic root and/or ascending aorta in 330 patients $(82.9 \%)$ and acute type A aortic dissection in 51 patients $(12.8 \%)$. Concomitant procedures were performed in 152 patients $(117$ of 312 men [37.5\%] and 35 of 86 women [40.7\%]; $P=.62$ ). Concomitant total aortic arch $(n=22)$ or partial arch replacement $(n=56)$ was performed in 78 patients. Of the 56 patients receiving partial arch replacement, 43 were men (13.8\% of 312 ) and 13 were women ( $15.1 \%$ of 86$)$. Of the 22 patients receiving total arch replacement, 14 were men ( $4.5 \%$ of 312$)$ and 8 were women $(9.3 \%$ of 86 ). Additional operative data are listed in Table 2.

The clinical data were completely drawn from our institutional database and patient records. All patients had provided written informed consent for their patient records and follow-up data to be used in an anonymized form for retrospective studies. Thus, additional patient consent was not required by the local ethics committee.

\section{Surgical Technique}

The modified button Bentall operation described by Kouchoukos and colleagues $^{8}$ was performed in all cases. The native aortic valve and the diseased part of the ascending aorta were resected after preparing 2 buttons from the native aorta, including the coronary ostia. However, it has been our institutional policy to avoid the use of felt strips to prevent adhesions from developing and facilitate downstream repair or reoperation, if necessary. All patients received an ATS aortic valved graft conduit (ATS Medical). If concomitant procedures were performed, mitral valve repair ( $n=18$ of 29$)$ or replacement $(n=11$ of 29$)$ were done after aortic valve excision. If coronary bypass grafting $(\mathrm{n}=51)$ was performed, the distal anastomoses were completed before the Bentall procedure. Arterial cannulation for cardiopulmonary bypass (CPB) depended on the extension of the diseased part of the aorta. The ascending aorta or proximal aortic arch were directly cannulated in most cases (303 of 398 patients [76\%]). Cannulation of the right or left femoral artery was mostly used when emergency cannulation was performed in hemodynamically unstable patients with type A dissection or if the aneurysm was in close proximity to the sternum $(\mathrm{n}=41$ of $398[10 \%])$. Cannulation of the right axillary artery $(\mathrm{n}=54[13.6 \%])$ was used if partial or complete arch replacement was anticipated (ie, in the case of acute type A dissection). Venous cannulation was usually performed through a 2 -stage catheter in the right atrium. Cannulation of the femoral vein was performed as an alternative cannulation site, mostly with cannulation of the femoral artery.

In accordance with the current guidelines, replacement of the ascending aorta was performed if the diameter exceeded 4.0 to $4.5 \mathrm{~cm}$ in bicuspid valve disease and $>5.0 \mathrm{~cm}$ in tricuspid aortic valve disease or rapid progression was documented on computed tomography scan or magnetic resonance imaging.

In most patients, intermittent cold antegrade crystalloid cardioplegia was used for myocardial protection (253 men [81\%] and 77 women [90\%]; $P=.08$ ), mostly Bretschneider HTK solution (Köhler Chemie,

TABLE 1. Preoperative patient characteristics

\begin{tabular}{|c|c|c|c|c|}
\hline Variable & All patients $(n=398)$ & $\operatorname{Men}(n=312)$ & Women $(n=86)$ & $P$ value \\
\hline Age (y) & $53 \pm 12(18-88)$ & $52 \pm 12(18-88)$ & $56 \pm 12(29-83)$ & .01 \\
\hline \multicolumn{5}{|l|}{ Risk factors } \\
\hline Hypertension & $228(57)$ & $181(58)$ & $47(55)$ & .54 \\
\hline History of smoking & $106(27)$ & $92(29)$ & $14(16)$ & .38 \\
\hline Diabetes & $24(6)$ & $20(6)$ & $4(5)$ & .80 \\
\hline COPD & $11(3)$ & $7(2)$ & $4(5)$ & .26 \\
\hline Hyperlipidemia & $98(25)$ & $85(27)$ & $13(15)$ & .02 \\
\hline \multicolumn{5}{|l|}{ Genetic disorder } \\
\hline Logistic EuroSCORE & $14.1 \pm 11.6$ & $13.5 \pm 11.5$ & $16.1 \pm 11.9$ & .01 \\
\hline \multicolumn{5}{|l|}{ Indication for root replacement } \\
\hline Type A dissection & $51(13)$ & $36(12)$ & $15(17)$ & .15 \\
\hline Aneurysm & $330(83)$ & 259 (83) & $71(83)$ & 1.00 \\
\hline Other & $7(2)$ & $7(2)$ & $0(0)$ & .35 \\
\hline Acute infective endocarditis & $10(3)$ & $10(3)$ & $0(0)$ & .12 \\
\hline \multicolumn{5}{|l|}{ Preoperative valve function } \\
\hline Normal & $3(1)$ & $3(1)$ & $0(0)$ & 1.00 \\
\hline Significant AR & $225(57)$ & $172(55)$ & $53(62)$ & .33 \\
\hline Significant AS & $43(11)$ & $30(10)$ & $13(15)$ & .17 \\
\hline AR plus AS & $127(32)$ & 107 (34) & $20(23)$ & .07 \\
\hline LVEF (\%) & $59 \pm 15$ & $58 \pm 15$ & $61 \pm 17$ & .07 \\
\hline BSA (Mosteller) & $1.99 \pm 0.59$ & $2.04 \pm 0.66$ & $1.81 \pm 0.19$ & $<.01$ \\
\hline
\end{tabular}

Data presented as mean \pm standard deviation (range) or n (\%). COPD, Chronic obstructive pulmonary disease; $A R$, aortic regurgitation; $A S$, aortic stenosis; $L V E F$, left ventricular ejection fraction; $B S A$, body surface area. 
TABLE 2. Operative data

\begin{tabular}{|c|c|c|c|c|}
\hline Variable & All patients $(n=398)$ & $\operatorname{Men}(n=312)$ & Women $(n=86)$ & $P$ value \\
\hline Previous cardiac surgery & $21(5)$ & $20(6)$ & $1(1)$ & .06 \\
\hline CPB time (min) & $146 \pm 79$ & $138 \pm 63$ & $132 \pm 80$ & .44 \\
\hline Minimal temp $\left({ }^{\circ} \mathrm{C}\right)$ & $29.6 \pm 4.9$ & $30.7 \pm 4.4$ & $29.0 \pm 5.0$ & .02 \\
\hline Ascending aorta diameter $(\mathrm{mm})$ & $55 \pm 10$ & $54 \pm 9$ & $56 \pm 14$ & .97 \\
\hline \multicolumn{5}{|l|}{ Concomitant procedures } \\
\hline CABG & $50(13)$ & $38(12)$ & $12(14)$ & .71 \\
\hline MV repair or replacement & $29(7)$ & $25(8)$ & $4(5)$ & .36 \\
\hline Aortic clamp time (min) & $94 \pm 37$ & $95 \pm 37$ & $89 \pm 37$ & .05 \\
\hline \multicolumn{5}{|l|}{ Operation extent } \\
\hline Ascending & $320(80)$ & $255(82)$ & $65(76)$ & .22 \\
\hline Ascending and hemiarch & $56(14)$ & $43(14)$ & $13(15)$ & .73 \\
\hline Ascending and arch & $22(6)$ & $14(4)$ & $8(9)$ & .11 \\
\hline Operative time (min) & $229 \pm 100$ & $231 \pm 94$ & $221 \pm 120$ & .03 \\
\hline \multicolumn{5}{|l|}{ Cannulation site } \\
\hline Ascending aorta or arch & $303(76)$ & $241(77)$ & $62(72)$ & .32 \\
\hline Femoral artery & $41(10)$ & $27(9)$ & $14(16)$ & .05 \\
\hline Axillary artery & $54(14)$ & $44(14)$ & $10(12)$ & .72 \\
\hline Prosthesis size $(\mathrm{mm})$ & $25 \pm 2$ & $26 \pm 2$ & $24 \pm 2$ & $<.01$ \\
\hline Bicuspid aortic valve & $142(36)$ & $114(37)$ & $28(33)$ & .53 \\
\hline Elephant trunk & $10(3)$ & $7(2)$ & $3(3)$ & .46 \\
\hline
\end{tabular}

Data presented as mean \pm standard deviation or $\mathrm{n}(\%) . C P B$, Cardiopulmonary bypass; $C A B G$, coronary artery bypass grafting; $M V$, mitral valve.

Alsbach-Hähnlein, Germany). Cold blood cardioplegia was used in 56 men $(18 \%$ of 312$)$ and 6 women $(7 \%$ of $86 ; P=.01)$. Three patients received St Thomas solution.

Antegrade selective cerebral protection was performed in 38 patients (31 men and 7 women; $P=.84$ ), as previously described. ${ }^{9}$ Unilateral selective cerebral protection by way of the right axillary artery was used in 15 male and 2 female patients $(P=.54)$. Bilateral selective cerebral protection, mostly by way of the axillary artery and an additional balloon perfusion catheter placed in the left carotid artery, was performed in 16 male and 5 female patients $(P=.79)$. CPB was discontinued if the body core temperature reached $36.5^{\circ} \mathrm{C}$.

\section{Follow-up}

Follow-up was performed using the data from our departmental database, which was supplemented from patient records. Our institutional database is continuously and prospectively maintained by our research personnel. Follow-up data for long-term survival or adverse outcomes are routinely recorded from direct telephone interviews with the patient, a close relative, or the referring physician. Current follow-up information (not older than 2 years) was available for $90.7 \%$ of the present.

\section{Statistical Analysis}

The data were entered in a Microsoft Excel worksheet (Microsoft Corp, Redmond, Wash) and transferred to SPSS (SPSS Statistics, version 17.0, IBM Germany, Ehingen, Germany) for statistical analysis. The characteristics are reported as the mean \pm standard deviation. Continuous data were analyzed using the Wilcoxon log-rank test or Mann-Whitney $U$ test. Kaplan-Meier life tables were calculated for long-time survival analysis. Categorical data were analyzed using the chi-square test or Fisher's exact test. Follow-up time for survival was measured from the date of the operation to either the date of death or the date of the last contact alive. The Cox proportional hazards model was used to examine the risk factors for long-term death. The assumptions of the proportional Hazards model were checked graphically. Univariate risk factors with $P<.1$ were included in the multivariate analysis.
To compare longevity to an age-matched normal population, survival data for an artificial control group was drawn from the life tables provided by the German Federal Statistical Service (Wiesbaden, Germany). The follow-up duration of the survivors for creation of the Kaplan-Meier life tables of this artificial control group were matched to the follow-up duration of the study group.

\section{RESULTS}

\section{Preoperative Patient Characteristics}

The patient characteristics are listed in Table 1. The mean age of the 398 patients included in the present study was 53 \pm 12 years. However, the women who underwent surgery were significantly older than were the men $(56 \pm 12$ years vs $52 \pm 12$ years; $P=.01$ ). Most risk factors were equally distributed in both groups, except for hyperlipidemia, which was more frequent in men $(27 \%$ vs $15 \% ; P=.02)$, and body surface area, which was also slightly elevated in men $\left(2.04 \pm 0.66 \mathrm{~m}^{2}\right.$ in men vs $1.81 \pm 0.10 \mathrm{~m}^{2}$ in women).

The mean logistic EuroSCORE was $14.1 \% \pm 11.6 \%$ and was about 3 points lower for the men $(13.5 \% \pm 11.5 \%)$ than for women $(16.1 \% \pm 11.9 \% ; P=.01)$. The indications and preoperative functional valve status were similar in both groups, without any statistical differences. Both groups had a similar number of emergency procedures (men, $15.4 \%$ vs women, $14.0 \% ; P=.87$ ).

\section{Intraoperative Data}

The intraoperative data are listed in detail in Table 2. Approximately $5 \%$ of the overall patient population had undergone previous cardiac surgery; however, a clear trend was seen toward more reoperative procedures in the men $(P=.06)$. A bicuspid valve was present in $36 \%$ of all cases 
(Table 2). Significant differences were noted in the lowest body core temperature (Table 2), although the number of patients requiring partial or complete arch replacement or with acute type A dissection was not different. However, a tendency was seen toward a greater proportion of women with acute type A aortic dissection (men, $12 \%$ vs women, $17 \% ; P=.15)$. The aortic crossclamp time was an average of 6 minutes longer in the male than in the female patients (95 \pm 37 vs $89 \pm 37$ minutes; $P=.05$ ), as was the duration of the surgical procedure $(231 \pm 94$ vs $221 \pm 120$ minutes; $P=.03$ ). In terms of concomitant procedures, both groups were similar (Figure 2).

Although the diameter of the ascending aorta (54 \pm 9 and $56 \pm 14 \mathrm{~mm} ; P=.97$ ) and the Svensson index (women, $13.9 \pm 4.9 \mathrm{~mm}^{2} / \mathrm{m}$ vs men, $13.7 \pm 6.0 \mathrm{~mm}^{2} / \mathrm{m} ; P=.37$ ) did not differ in either group, women received a statistically significantly smaller valve prosthesis than men $(26 \pm 2 \mathrm{~mm}$ vs $24 \pm 2 \mathrm{~mm}, P<.01)$. After adjusting for the body surface area, this resulted in an effective orifice area index of $1.69 \pm 0.33 \mathrm{~cm}^{2} / \mathrm{m}^{2}$ in men versus $1.54 \pm 0.32 \mathrm{~cm}^{2} / \mathrm{m}^{2}$ in women $(P<.01)$. No case of severe patient-prosthesis mismatch (PPM), defined as an effective orifice area index of $<0.65 \mathrm{~cm}^{2} / \mathrm{m}^{2}$, occurred.

\section{Hospital Mortality}

Overall hospital mortality, defined as death within 30 days postoperatively or before hospital discharge, was $7.5 \%$, and did not differ statistically between the 2 groups (30 patients; men, 6.7\%; women, women, $10.0 \%$; $P=.25)$. The main cause of death was low cardiac output in 9 patients ( 8 men and 1 woman), followed by irreversible

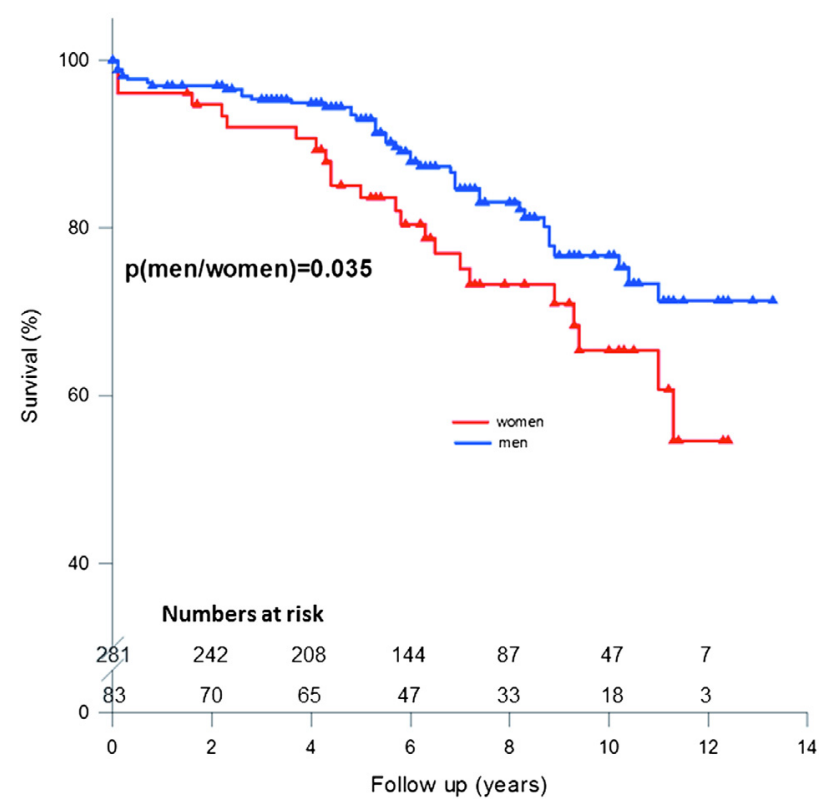

FIGURE 1. Long-term survival after aortic root replacement in male and female patients. Long-term survival was inferior for women compared with men, but women presented at a significantly older age. cerebral ischemia in 6 (4 men and 2 women). Other causes were sepsis in 4 ( 3 men and 1 woman), multiorgan failure in 2 (both men), hemorrhagic shock in 2 ( 1 man and 1 woman), acute respiratory distress syndrome in 1 man, nonsurgical bleeding in 1 woman, and bleeding in 1 woman from the proximal anastomosis with consecutive hemorrhagic shock. Four patients ( 2 men and 2 women) died of unknown causes, with an autopsy denied by their next of kin.

The significant univariate risk factors for operative mortality are listed in Table 3.

\section{Reoperation Rate}

Freedom from aorta-related reoperation was $97.2 \%$ after 12 years. Five male $(1.6 \%)$ and six female patients $(7.0 \%)$ required reoperation $(P=.02)$. Nine patients (3 men and 6 women; $P<.01)$ required additional downstream repair (either conventional or endovascular stent implantation) because of aortic disease progression and the development of a thoracoabdominal aortic aneurysm. Two male patients required reoperation because of prosthetic valve endocarditis 1 and 10 years after the initial operation.

\section{Long-Term Outcome}

The average follow-up period was 7.4 years (range, $0-13$; 2366 cumulative patient-years). Crude 5-year survival was significantly better among the male than the female patients (men, $87.2 \% \pm 2.0 \%$ vs women, $76.6 \% \pm$ $4.7 \%, P=.03$ ) and was consistent at 10 years of follow-up (men, $71.1 \% \pm 3.7 \%$ vs women, $59.9 \% \pm 6.3 \%$; $P=.03$ ). The Kaplan-Meier estimate for long-term survival is shown in Figure 1. Compared with an age-matched normal population, the overall long-term survival for women-but not for men-remained significantly worse (Figure 2).

The long-term events included stroke in 16 patients (11 men vs 5 women; $P=.35$ ) at a mean of 5 years postoperatively, and gastrointestinal bleeding in 10 patients $(6$ men vs 4 women; $P=.23$ ) at a mean of 2 years postoperatively.

The multivariate risk factors for long-term death were age at surgery $(P<.01)$, crossclamp time $(P<.01)$, diabetes $(P=.04)$, and partial $(P<.01)$ or complete $(P<.01)$ arch replacement (Table 4$)$. The presence of a bicuspid aortic valve and concomitant coronary artery bypass grafting were significant risk factors on univariate analysis; however, they were not confirmed as independent risk factors on multivariate analysis.

The known causes of long-term death were cancer (5 men and 2 women), sepsis ( 1 man and 1 woman), acute hepatitis ( $1 \mathrm{man})$, terminal congestive heart failure ( 3 men and 2 women), sudden cardiac death ( 2 men), multiorgan failure (1 woman), and pulmonary embolism (1 woman).

\section{Analysis of Different Age-Related Subgroups}

In an artificial subgroup that excluded patients $>60$ years old, with a similar mean age between the male and female 

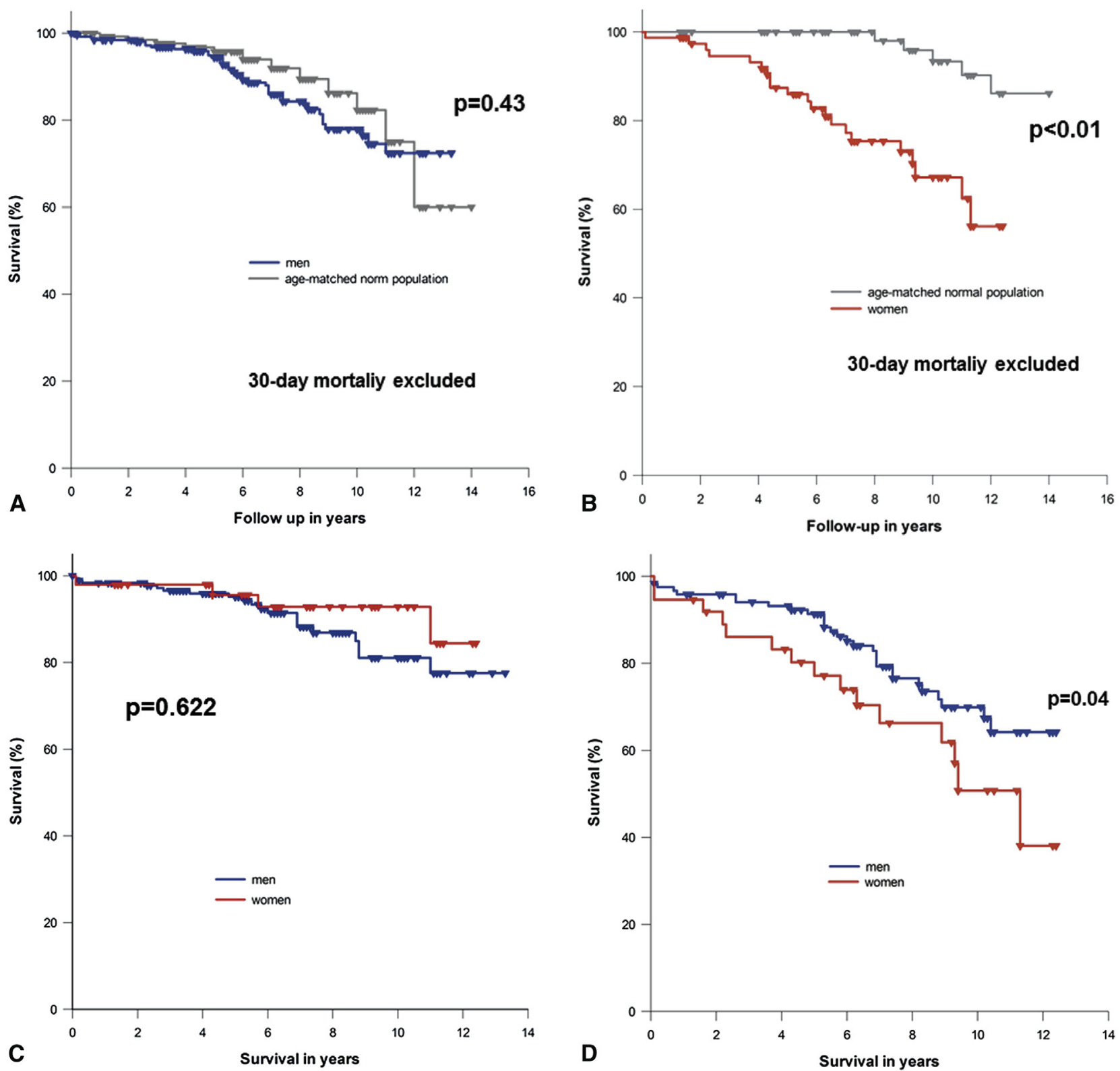

FIGURE 2. Long-term survival in (A) men and (B) women versus age-matched normal population. Although men experienced long-term survival comparable to that of their age-matched peers, the survival for women was significantly worse to an age-matched normal population. C, In an artificial subgroup, excluding patients aged $>60$ years (including 186 men and 48 women at risk, with $27 \mathrm{vs} 7$ events), men and women had similar long-term survival $(P=.622)$. D, However, in patients aged 55 to 75 years (including 129 men and 41 women at risk, with 39 vs 20 events), long-term survival was significantly better in men $(P=.04)$.

patients at surgery, the long-term survival was no longer different (men, $74 \% \pm 6 \%$ vs women, $77 \% \pm 11 \%$ after 12 years; $P=.62$; Figure $2, C$ ).

However, when comparing the age-related subgroups, a significant difference in 10-year survival was only found between men and women aged 60 to 70 years (Figure 3). Because the decision to choose a mechanical prosthesis for a patient older than 75 years is rarely expedient, an additional subgroup analysis was performed, excluding patients $<55$ years old and $>75$ years old. In this subgroup, with a similar age for the men and women (women, $63.8 \pm$ 5.0 years vs men, $62.2 \pm 43.5$ years; $P=.51$ ), long-term survival was significantly better among the men (men, $60 \%$ $\pm 6 \%$ vs women, $33 \% \pm 12 \%$ after 10 years; $P=.04$ ). In contrast, no statistically significant difference was found in an age-matched subgroup $\leq 55$ years of age (men, $93 \% \pm 2 \%$ vs women, $94 \% \pm 4 \%$ after 5 years; men, $84 \% \pm 4 \%$ vs women, $91 \% \pm 5 \%$ after 10 years; $P=.66$ ).

Because the difference in survival in men and women seemed to be critical between the age of 60 and 75 years, 
TABLE 3. Risk factors for operative mortality

\begin{tabular}{lccc}
\hline \multicolumn{1}{c}{ Variable } & $\begin{array}{c}\text { Patients } \\
\text { surviving } \\
(\mathbf{n = 3 6 8 )}\end{array}$ & $\begin{array}{c}\text { Patients } \\
\text { with OM } \\
(\mathbf{n}=\mathbf{3 0})\end{array}$ & $\begin{array}{c}\boldsymbol{P} \\
\text { value }\end{array}$ \\
\hline Age (y) & $52.4 \pm 12.2$ & $60.0 \pm 11.3$ & $<.01$ \\
Risk factors & & & \\
$\quad$ Hypertension & $209(56.8)$ & $19(63.3)$ & .58 \\
History of smoking & $100(27.2)$ & $6(20.0)$ & .52 \\
Diabetes & $20(5.4)$ & $4(13.3)$ & .10 \\
COPD & $11(3.0)$ & $0(0)$ & 1.0 \\
Hyperlipidemia & $91(24.7)$ & $7(23.3)$ & 1.0 \\
$\quad$ BSA & $2.02 \pm 0.22$ & $1.64 \pm 2.02$ & .27 \\
Previous cardiac surgery & $18(4.9)$ & $3(10)$ & .45 \\
Logistic EuroSCORE & $13.1 \pm 10.5$ & $25.8 \pm 17.7$ & $<.01$ \\
CPB time (min) & $137 \pm 69$ & $250 \pm 117$ & $<.01$ \\
Operation extent & & & \\
$\quad$ Ascending and partial arch & $48(13.0)$ & $8(26.7)$ & .05 \\
Ascending and arch & $18(4.9)$ & $4(13.3)$ & .07 \\
Type A dissection & $33(9.0)$ & $11(36.7)$ & $<.01$ \\
\hline
\end{tabular}

Data presented as mean \pm standard deviation or $\mathrm{n}(\%)$. OM, Operative mortality; $C O P D$, chronic obstructive pulmonary disease; $B S A$, body surface area; $C P B$, cardiopulmonary bypass.

we performed an additional risk factor analysis with this subgroup (Table 5). In contrast to the risk factor analysis results listed in Table 4, female gender presented as a significant risk factor for late mortality (hazard ratio, $2.07 ; P=.03)$ in this specific age group.

\section{DISCUSSION}

The long-term results have been excellent for aortic root replacement with a mechanically valved conduit. However, the recent idea that female gender might be associated with an inferior prognosis after aortic surgery, in particular with regard to long-term outcome, could profoundly affect the conduit choice for women. Zehr and colleagues ${ }^{10}$ found female gender was a significant univariate risk factor for late death in their series of 203 patients undergoing aortic root surgery. Likewise, female gender was an independent risk factor for late death after bioprosthetic root replacement in 275 patients in a recently published cohort

TABLE 4. Multivariate predictors of long-term mortality $(n=75$ events)

\begin{tabular}{llcr}
\hline \multicolumn{1}{c}{ Variable } & HR & $\mathbf{9 5} \% \mathbf{C I}$ & $\boldsymbol{P}$ value \\
\hline Age at surgery & 1.06 & $1.04-1.09$ & $<.01$ \\
Diabetes & 2.46 & $1.10-5.49$ & .03 \\
CPB time & 1.003 & $1.002-1.004$ & $<.01$ \\
Partial arch & 2.43 & $1.30-4.56$ & $<.01$ \\
Total arch & 3.66 & $1.73-7.74$ & $<.01$ \\
CABG & 1.13 & $0.62-2.06$ & .70 \\
Tricuspid AV & 1.46 & $0.88-2.43$ & .14 \\
BSA & 0.85 & $0.70-1.02$ & .08 \\
Gender & 1.06 & $0.63-1.77$ & .84 \\
\hline
\end{tabular}

$H R$, Hazard ratio; $C I$, confidence interval; $C P B$, cardiopulmonary bypass; $C A B G$, coronary artery bypass grafting; $A V$, aortic valve; $B S A$, body surface area.

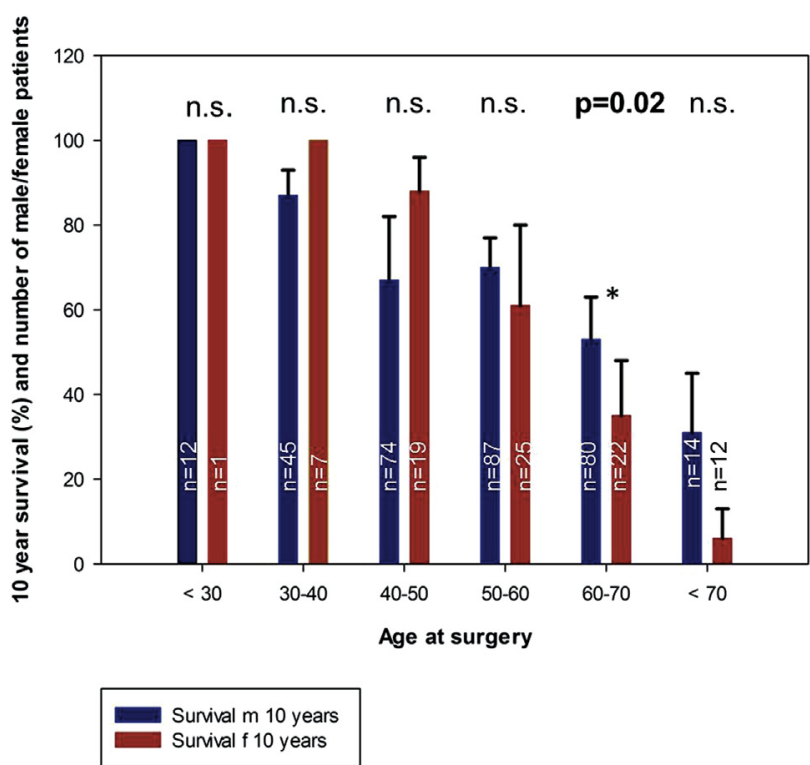

FIGURE 3. Ten-year survival in men versus women in different agerelated groups. The blue and red bars depict survival in men versus women calculated using Kaplan-Meier estimates in the age-related subgroups. Significant differences in long-term survival were only found in patients aged 60 to 70 years. n.s., Not significant.

from Mount Sinai Hospital. ${ }^{7}$ Accordingly, the intention of the present study was to evaluate the influence of gender on long-term outcomes after mechanical aortic root replacement.

The results of our study support the assumption of these recently published series, suggesting that long-term survival after aortic root replacement is inferior for women. Several reasons could explain this major finding of our study. First, the women who presented for surgery were significantly older than the men were, just as described in most studies interrelating cardiac surgical procedures and age and gender. The logistic EuroSCORE was significantly greater for the women, a finding also in line with most published series concerned with gender-dependent outcome differences after cardiac surgical procedures. ${ }^{11,12}$ However, the indication for aortic root replacement and important known preoperative risk factors were equally distributed among the men and women, except for hyperlipidemia, which was significantly more prevalent among the men (Table 1). Hence, this could also be a side effect of the

TABLE 5. Multivariate predictors of long-term mortality in patients aged 60 to 75 years $(n=38$ events $)$

\begin{tabular}{lccc}
\hline \multicolumn{1}{c}{ Variable } & HR & $\mathbf{9 5} \% \mathbf{C I}$ & $\boldsymbol{P}$ value \\
\hline CPB time & 1.006 & $1.001-1.011$ & .02 \\
Partial arch & 2.61 & $1.20-5.67$ & .02 \\
Previous cardiac surgery & 4.66 & $0.71-30.5$ & .11 \\
Gender (female) & 2.07 & $1.09-3.93$ & .03 \\
\hline
\end{tabular}

$H R$, Hazard ratio; $C I$, confidence interval; $C P B$, cardiopulmonary bypass. 
age disparity in both groups. The body surface area was also slightly elevated in men but neither was a risk factor for operative mortality nor long-term mortality.

We investigated several clinical relevant risk factors that might have influenced long-term survival in both groups. However, we did not test all the risk factors included in the EuroSCORE because of limited data availability. Hence, gender might still have been a surrogate variable for other factors not represented in our risk factor analysis. Therefore, it would be premature to draw clinical decisions from the present single retrospective study. However, the reasons for the difference in long-term survival after mechanical aortic root replacement should be examined further.

Second, gender-related anatomic disparities with regard to the dimension of the aortic valve and the native root and ascending aorta could play an important role. Multiple investigations were performed to study aortic root dilatation among men and women, in which age was an important factor. Owing to the specific phases of life for men and women, the aortic root showed major discrepancies at certain age decades. Beller and colleagues ${ }^{13}$ reported in their investigation of the noncoronary sinus that the overall curvature of the sinus wall among women of all ages showed a specific pattern. Beller and colleagues ${ }^{13}$ termed it "pronounced." In contrast, the sinus wall of younger men is rather straight and curves in later periods of life. Genetic predispositions implicating a gender-specific wall structure that results in different wall stress, in particular during the reproductive years and in specific aortic regions related to activity of matrix metalloproteinases might explain these findings.

When investigating aortic dissection during pregnancy, Immer and colleageus ${ }^{14}$ found aortic root enlargement up to $>4 \mathrm{~cm}$ during pregnancy exclusively in these patients, with bicuspid aortic valve and Marfan syndrome consecutively representing a considerable risk factor for the occurrence of acute type A dissection.

Mulder and Meijboom ${ }^{15}$ studied the effect of gender on aortic root growth in patients with Marfan syndrome and found that reducing the cutoff value from 5 to $3 \mathrm{~mm}$ prevented women from developing type A dissection. Specifically, among patients with Marfan syndrome, it remains disputable whether the increased aortic root diameter is the most important cardiovascular risk factor compared with decreased aortic root distensibility. Additionally, the SMAD-3 mutation has been associated with frequent dilatation of the aorta, in particular, of the aortic root. ${ }^{16-18}$

When excluding 30-day mortality, postoperative long-term survival in women was inferior to that of an age-matched normal population $(P<.01$; Figure 2$)$. However, survival in men seemed equivalent to that of their age-matched peers $(P=.43)$.
By excluding patients aged $<55$ years, we tried to determine whether long-term survival might be influenced by the hormonal changes associated with menopause. Additionally, we excluded the elderly (age, $>75$ years) with very specific individual considerations that resulted in the choice of a mechanically valved conduit (eg, the presence of another mechanical valve) and confounded the outcome analysis. In this artificial subgroup, the women had long-term survival that was clearly inferior to that of the men $(P=.04)$. The reasons for this finding and whether these results will also apply to patients receiving biologic root replacement are currently under investigation. However, these findings should be interpreted with caution, because they were from a nonmatched subgroup analysis with smaller patient numbers.

The general surgical setup was generally the same for all patients. However, the mean aortic crossclamp time and mean operative time were significantly longer for the men, possibly owing to the greater number of redo surgeries among the men $(6 \%$ vs $1 \% ; P=.06)$. The average minimal body core temperature was about $2^{\circ} \mathrm{C}$ lower in the women. Although it did not reach statistical significance, a possible explanation might be that the proportion of female patients receiving complete arch replacement was twice that of the male patients requiring complete arch replacement $(4 \%$ of men vs $9 \%$ of women; $P=.11$ ). Furthermore, female patients had a significantly greater rate of femoral cannulation, which has been shown to be associated with unfavorable outcomes in atherosclerotic aneurysms ${ }^{19}$ and, therefore, might have contributed to the inferior outcomes for women in our study.

The mean prosthesis size was significantly smaller in the women $(26 \pm 2 \mathrm{~mm}$ in men vs $24 \pm 2 \mathrm{~mm}$ in women; $P<.0001$ ). This might have been because of the smaller cardiac weight and size among women in relation to their body surface area. Even after adjusting for the body mass index, the results were significantly different between the 2 groups. Saxena and colleagues ${ }^{20}$ reported similar findings about valve size implantation in male and female patients $(23.8 \pm 1.8 \mathrm{~mm}$ in men vs $21.2 \pm 1.7 \mathrm{~mm}$ in women; $P<.001$ ). Howell and colleagues ${ }^{21}$ found that calculated PPM was more common in women. In their study, $62 \%$ of moderate PPM, with an effective orifice area index of $<0.85 \mathrm{~cm}^{2} / \mathrm{m}^{2}$ but $>0.6 \mathrm{~cm}^{2} / \mathrm{m}^{2}$, and $92 \%$ of severe PPM, with an effective orifice area index of $<0.6 \mathrm{~cm}^{2} / \mathrm{m}^{2}$, affected female patients.

\section{Hospital Mortality}

Overall hospital mortality was $7.4 \%$, statistically equal in both groups $(P=.25)$. Similar to that in our patient population, Pacini and colleagues ${ }^{22}$ showed an early mortality rate of $6.9 \%$. Multivariate analysis showed that a CPB time $>180$ minutes (odds ratio, 12.5; confidence interval, 3.9-40.3; $P<.001)$ and concomitant bypass 
surgery (odds ratio, 4.6; 95\% confidence interval, 1.2-17.7; $P=.025)$ were independent risk factors for early mortality. Again, these findings were expected and in line with our results. The risk factors that were associated with early mortality in our study were CPB time, age at surgery, acute type A dissection, and concomitant partial or complete arch replacement.

The reasons for early mortality in our study were similar to previously published data. Joo and colleagues ${ }^{23}$ reported a hospital mortality of $5.5 \%$ in 12 patients, with the mean cause low cardiac output syndrome in $3(25 \%)$, arrhythmia in $3(25 \%)$, pneumonia in $2(17 \%)$, sepsis in $2(17 \%)$, and others.

\section{Reoperation Rate}

Freedom from aorta-related reoperation was $97.2 \%$ during the follow-up period. Most patients in our study required downstream repair because of either type B aortic dissection or aneurysm formation of the descending and/or abdominal aorta. We observed a greater reoperation rate in women than in men ( 5 men vs 6 women; $P=.02$ ). Because these reoperations were mainly downstream repairs, this might have resulted from a different type of aneurysm formation in women. Only 2 patients required reoperation because of prosthetic valve endocarditis. Even more striking, no reoperations were required for valve thrombosis, indicating that valve thrombosis is not a major problem with these new-generation mechanical aortic valves.

\section{Study Limitations}

The major limitation of the present study was its retrospective character. Therefore, the study could have been subject to a selection bias, because the patients were not randomly assigned for the implantation of a mechanical valve prosthesis. Current guidelines have suggested the use of a bioprosthetic valve or a more aggressive attempt at a reconstructive technique in young female patients wishing to become pregnant, which might be an explanation for the age disparities in both groups. A prospective multicenter trial is required to confirm our finding that women present late for surgery of the aortic root. Also, female patients' individual reproductive history might play an important role in aneurysm formation in women; however, detailed information concerning reproductive history was not available from our institutional database or our patient records. Finally, the results of our subgroup analyses were based on small patient numbers and therefore should be evaluated further in multicenter trials to gain significant patient numbers and well-matched groups.

\section{CONCLUSIONS}

Overall, long-term survival after mechanical aortic root replacement was significantly better among men. However, this was in part because women with aortic root pathologic entities presented for surgery at a significantly older age and had a significantly greater EuroSCORE than their male peers. Comparing age-matched subgroups $\leq 55$ years old, women and men had no significantly different life expectancy after mechanical root replacement. However, in contrast to male patients, the longevity of the female patients after age 55 years was inferior to that of their age-matched peers.

\section{References}

1. Misfeld M, Bechtel M, Sievers HH. Types of reconstructive surgery of the aortic valve. J Cardiovasc Surg (Torino). 2007;48:781-90.

2. Bechtel JF, Erasmi AW, Misfeld M, Sievers HH. Reconstructive surgery of the aortic valve: the Ross, David, and Yacoub procedure. Herz. 2006;31:413-22.

3. Minakata K, Schaff HV, Zehr KJ, Dearani JA, Daly RC, Orszulak TA, et al. Is repair of aortic valve regurgitation a safe alternative to valve replacement? J Thorac Cardiovasc Surg. 2004;127:645-53.

4. Etz CD, Bischoff MS, Bodian C, Roder F, Brenner R, Griepp RB, et al. The Bentall procedure: is it the gold standard? A series of 597 consecutive patients. J Thorac Cardiovasc Surg. 2010;140:S64-70.

5. Bentall H, De Bono A. A technique for complete replacement of the ascending aorta. Thorax. 1968;23:338-9.

6. Kouchoukos NT, Karp RB, Lell WA. Replacement of the ascending aorta and aortic valve with a composite graft: results in 25 patients. Ann Thorac Surg. 1977;24:140-8.

7. Etz CD, Homann TM, Rane N, Bodian CA, Di Luozzo G, Plestis KA, et al. Aortic root reconstruction with a bioprosthetic valve conduit: a consecutive series of 275 procedures. J Thorac Cardiovasc Surg. 2007;133:1455-63.

8. Kouchoukos NT, Wareing TH, Murphy SF, Perillo JB. Sixteen year experience with aortic root replacement: results of 172 operations. Ann Surg. 1991;214: 308-20.

9. Misfeld M, Leontyev S, Borger MA, Gindensperger O, Lehmann S, Legare JF, et al. What is the best strategy for brain protection in patients undergoing aortic arch surgery? A single center experience of 636 patients. Ann Thorac Surg. 2012; 93:1502-8.

10. Zehr KJ, Orszulak TA, Mullany CJ, Matloobi A, Daly RC, Dearani JA, et al. Surgery for aneurysms of the aortic root: a 30-year experience. Circulation. 2004; 110:1364-71.

11. Al-Alao BS, Parissis H, McGovern E, Tolan M, Young VK. Gender influence in isolated coronary artery bypass graft surgery: a propensity match score analysis of early outcomes. Gen Thorac Cardiovasc Surg. 2012;60:417-24.

12. Ad N, Barnett SD, Speir AM. The performance of the EuroSCORE and the Society of Thoracic Surgeons mortality risk score: the gender factor. Interact Cardiovasc Thorac Surg. 2007;6:192-5.

13. Beller CJ, Maurer $T$, Labrosse MR, Mesana $T$, Krack M, Veinot JP. Gender-specific differences in aortic sinus curvature during aging: an anatomical and computational study. Cardiovasc Pathol. 2009;18:148-55.

14. Immer FF, Bansi AG, Immer-Bansi AS, McDougall J, Zehr KJ, Schaff HV, et al. Aortic dissection in pregnancy: analysis of risk factors and outcome. Ann Thorac Surg. 2003;76:309-14.

15. Mulder BJ, Meijboom LJ. Pregnancy and Marfan syndrome: an ongoing discussion. J Am Coll Cardiol. 2012;60:230-1.

16. Donnelly RT, Pinto NM, Kocolas I, Yetman AT. The immediate and long-term impact of pregnancy on aortic growth rate and mortality in women with Marfan syndrome. J Am Coll Cardiol. 2012;60:224-9.

17. van de Laar IM, Oldenburg RA, Pals G, Roos-Hesselink JW, de Graaf BM, Verhagen JM, et al. Mutations in SMAD3 cause a syndromic form of aortic aneurysms and dissections with early-onset osteoarthritis. Nat Genet. 2011;43: 121-6.

18. van der Linde D, van de Laar IM, Bertoli-Avella AM, Oldenburg RA, Bekkers JA, Mattace-Raso FU, et al. Aggressive cardiovascular phenotype of aneurysms - osteoarthritis syndrome caused by pathogenic SMAD3 variants. J Am Coll Cardiol. 2012;60:397-403.

19. Etz CD, Plestis KA, Kari FA, Silovitz D, Bodian CA, Spielvogel D, et al. Axillary cannulation significantly improves survival and neurologic outcome after atherosclerotic aneurysm repair of the aortic root and ascending aorta. Ann Thorac Surg. 2008;86:441-6. 
20. Saxena A, Poh CL, Dinh DT, Reid CM, Smith JA, Shardey GC, et al. Does patient gender affect outcomes after concomitant coronary artery bypass graft and aortic valve replacement? An Australian Society of Cardiac and Thoracic Surgeons Database Study. Cardiology. 2011;119:116-23.

21. Howell NJ, Keogh BE, Ray D, Bonser RS, Graham TR, Mascaro J, et al. Patient-prosthesis mismatch in patient with aortic stenosis undergoing isolated aortic valve replacement does not affect survival. Ann Thorac Surg. 2010;89: 60-4.

22. Pacini D, Ranocchi F, Angeli E, Settepani F, Pagliaro M, Martin-Suarez S, et al Aortic root replacement with composite valve graft. Ann Thorac Surg. 2003;76:90-8.

23. Joo HC, Chang BC, Youn YN, Yoo KJ, Lee S. Clinical experience with the Bentall procedure: 28 years. Yonsei Med J. 2012;53:915-23. 